KANSAS JOURNAL of MEDICINE

\section{Annual Report of the Kansas Poison Control Center at The University of Kansas Health System}

Elizabeth Silver, Pharm.D., Lisa K. Oller, Pharm.D., Kathy White, R.N., Doyle M. Coons, R.N., Stephen L. Thornton, M.D. University of Kansas Health System, Kansas City, KS Kansas Poison Control Center

Received Nov. 28, 2020; Accepted for publication. Jan. 28, 2021; Published online April 19, 2021 https: doi.org 10.17161 lijm.voll414886

\section{ABSTRACT}

Introduction. This is the 2019 Annual Report of the Kansas Poison Control Center (KSPCC) at The University of Kansas Health System. The KSPCC is one of 55 certified poison control centers in the United States and serves the state of Kansas 24-hours a day, 365 days a year with certified specialists in poison information and clinical and medical toxicologists. The KSPCC receives calls from the public, law enforcement, health care professionals, and public health agencies. All calls to the KSPCC are recorded electronically in the Toxicall ${ }^{\varpi}$ data management system and uploaded in near real-time to the National Poison Data System (NPDS) which is the data repository for all poison control centers in the United States.

Methods. All encounters reported to the KSPCC from January 1, 2019 through December 31, 2019 were analyzed. Data recorded for each exposure includes caller location, age, weight, gender, exposure substance, nature of exposure, route of exposure, interventions, medical outcome, disposition, and location of care. Encounters were classified as human exposure, animal exposure, confirmed non-exposure, or information call (no exposure reported).

Results. The KSPCC logged 20,589 total encounters in 2019, including 19,406 human exposure cases. The KSPCC received calls from every county in Kansas. A slim majority of human exposure cases (50.5\%, $\mathrm{n}=9,790)$ were female. Approximately $61 \%(\mathrm{n}=11,876)$ of human exposures involved a child (defined as 19 years of age or less). Most encounters occurred at a residence $(91.6 \%, \mathrm{n}=17,780)$ and most cases $(64.9 \%, \mathrm{n}=12,599)$ originated from a residence. The majority of human exposures $(85.5 \%, \mathrm{n}=16,589)$ were acute cases (exposures occurring over 8 hours or less). Ingestion was the most common route of exposure documented $(85.3 \%, \mathrm{n}=16,548)$. The most commonly reported substance in pediatric (children $\leq 5$ ) encounters was cosmetics/personal care products $(\mathrm{n}=959)$ followed closely by household cleaning products $(n=943)$. For adult encounters, analgesics $(n=1,296)$ and sedative/hypnotics/antipsychotics $(\mathrm{n}=1,084)$ were the most frequently involved substances. Unintentional exposures were the most common reason for exposures $(75.4 \%, \mathrm{n}=14,634)$. Most encounters $(65.9 \%, \mathrm{n}$ $=12,780$ ) were managed in a non-healthcare facility (i.e., a residence). Among human exposures, 14,591 involved exposures to pharmaceutical agents while 9,439 involved exposure to non-pharmaceuticals. Medical outcomes were 26.4\% ( $\mathrm{n}=5,116)$ no effect, $18.8 \%(\mathrm{n}=3,652)$ minor effect, 9.3\% $(n=1,813)$ moderate effect, and 3.1\% $(n=603)$ major effects. There were 14 deaths in 2019 reported to the KSPCC. Cases from healthcare facilities and cases with moderate or major medical outcomes increased in 2019 compared to 2018. The number of deaths reported to the KSPCC increased in 2019 to 14 from 7 in 2018.

Conclusions. The results of the 2019 Kansas Poison Control Center's annual report demonstrated that cases were received from the entire state of Kansas totaling over 19,400 human exposures per year. While pediatric exposures remained the most common encounter, there continued a trend of increasing number of cases from healthcare facilities and for cases with serious outcomes. The experience of the KSPCC is comparable to national data. This report supported the continued value of the KSPCC to both public and acute health care in the state of Kansas.

\section{Kans J Med 2021;14:87-94}

\section{INTRODUCTION}

This is the 2019 Annual Report of Kansas Poison Control Center at The University of Kansas Health System (KSPCC). The KSPCC is a 24-hour 365 day/year health care information resource serving the state of Kansas. It was founded in 1982 and is one of the 55 poison control centers certified by the American Association of Poison Control Centers (AAPCC) in the United States. The KSPCC is staffed by 10 certified specialists in poison information who are either critical care trained nurses or Doctors of Pharmacy. There is 24-hour back-up provided by five board-certified clinical and medical toxicologists.

The KSPCC receives calls from the public, law enforcement, health care professionals, and public health agencies. Encounters may involve an exposed animal or human (Exposure Call) or a request for information with no known exposure (Information Call). The KSPCC follows all cases to make management recommendations, monitor case progress, and document medical outcome. This information is recorded electronically in the Toxicall ${ }^{\varpi}$ data management system and uploaded in near real-time to the National Poison Data System (NPDS).

NPDS is the data warehouse for all the nation's poison control centers. ${ }^{1}$ The average time to upload data for all poison centers is 7.72 $[6.90,12.00]$ (median $[25 \%, 75 \%]$ ) minutes creating a near real-time national exposure database and surveillance system. The KSPCC has the ability to share NPDS real time surveillance with state and local health departments and other regulatory agencies. The analysis and summary of all encounters reported to the KSPCC from January 1, 2019 to December 31, 2019 is reported below.

\section{METHODS}

All KSPCC encounters recorded electronically in the Toxicall ${ }^{\circledast}$ data management system from January 1, 2019 to December 31, 2019 were analyzed. Cases were first classified as either an exposure or suspected exposure (human exposure, animal exposure, non-exposure confirmed cases) or a request for information with no reported exposure (information call). Extracted data included caller location, age, weight, gender, exposure substance, number of follow-up calls, nature of exposure (i.e., unintentional, recreational, or intentional), exposure scenario, route of exposure (oral, dermal, parenteral), interventions, medical outcome (no effect, minor, moderate, severe, or death), disposition (admitted to noncritical care unit, admitted to critical care

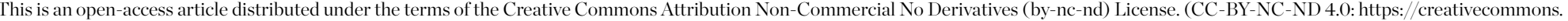
org/licenses/by-nc-nd/4.0/) 
unit, admitted to psychiatry unit, lost to follow-up, or treated and released) and location of care (non-health care facility or health care facility). For this analysis, a pediatric case was defined as any patient 19 years of age or less. This was consistent with NPDS methodology. Similarly, NPDS descriptions of the medical outcomes of cases were used: minor - minimally bothersome symptoms, moderate - more pronounced symptoms, usually requiring treatment, and major - life threatening signs and symptoms. Data were analyzed using Microsoft Excel (Microsoft Corp, Redmond, WA).

\section{RESULTS}

The KSPCC logged 20,589 total calls in 2019. This was a decrease of 483 calls (2.3\%) compared to 2018. Among the calls in 2019 were 19,406 human exposure cases, 62 non-exposure confirmed cases, 125 animal exposure cases, and 996 information calls. For information calls, drug information $(\mathrm{n}=327)$ was most common reason for calling. Table 1 describes the encounter types.

The KSPCC made 33,724 follow-up calls in 2019. Follow-up calls were done in $58.2 \%$ of human exposure cases. One follow-up call was made in $23.7 \%$ of human exposure cases and multiple follow-up calls (range 2 - 48) were made in $34.5 \%$ of cases. For human exposure cases which required a follow-up call, an average of three follow-up calls were performed per case. This was a $7 \%$ increase in the number of follow-up calls performed compared to 2018.

The KSPCC received calls from all 105 counties and every hospital in Kansas. The county with the largest number of calls was Sedgwick County with 3,115. In addition, calls were received from all 50 states, and the District of Columbia.

Table 1. Encounter type.

\begin{tabular}{|c|c|c|}
\hline & Number & $\%$ \\
\hline \multicolumn{3}{|l|}{ Exposure } \\
\hline Human exposure & 19,406 & 99.36 \\
\hline Animal exposure & 125 & 0.64 \\
\hline Subtotal & 19,531 & 94.86 \\
\hline \multicolumn{3}{|l|}{ Non-exposure confirmed cases } \\
\hline Human non-exposure & 62 & 100.00 \\
\hline Subtotal & 62 & 0.30 \\
\hline \multicolumn{3}{|l|}{ Information call } \\
\hline Drug information & 327 & 32.83 \\
\hline Drug identification & 81 & 8.13 \\
\hline Environmental information & 71 & 7.13 \\
\hline Medical information & 24 & 2.41 \\
\hline Occupational information & 1 & 0.10 \\
\hline Poison information & 94 & 9.44 \\
\hline Prevention/safety/education & 9 & 0.90 \\
\hline Teratogenicity information & 2 & 0.20 \\
\hline Other information & 43 & 4.32 \\
\hline Substance abuse & 8 & 0.80 \\
\hline Administrative & 22 & 2.21 \\
\hline Caller referred & 314 & 31.53 \\
\hline Subtotal & 996 & 4.84 \\
\hline Total & 20,589 & 100.00 \\
\hline
\end{tabular}

\section{KANSAS JOURNAL of MEDICINE}

2019 KSPCC REPORT

continued.

Overall, a slim majority of human exposure cases $(50.5 \%, \mathrm{n}=$ $9,790)$ were female. In children younger than 13 years of age a majority were male, but this gender distribution was reversed in teenagers and adults. In fact, in the age group involving children 13-19 years of age, $61.3 \%$ of cases were female. Approximately $61.2 \%(n=11,876)$ of human exposures involved a child (defined as age 19 years or less).

Table 2 illustrates distribution of human exposures by age and gender. Patients one year of age were the most common age group involved in encounters reported to the KSPCC. For adults, the age group of 20 - 29 years old was most encountered. Seventy exposures occurred in pregnant women ( $0.4 \%$ of all human exposures). Of these exposures, $28.6 \%$ occurred in the first trimester, $35.7 \%$ occurred in the second trimester, and $34.2 \%$ occurred in the third trimester. Most exposures in pregnant women (68.6\%) were unintentional exposures with $30 \%$ resulting from intentional exposures. There was one reported death to KSPCC in a pregnant woman in 2019.

For human exposures, $64.9 \%(\mathrm{n}=12,599)$ of calls originated from a residence (own or other), while 91.6\% ( $\mathrm{n}=17,780)$ of these exposures occurred at a residence (own or other). Calls from a health care facility accounted for $25.8 \%(n=5,168)$ of human exposure encounters. Table 3 further details the origin of human exposure cases and the site of the exposure. The majority of human exposures, $85.5 \%$ ( $\mathrm{n}=$ 16,589) were acute cases defined as exposures occurring over 8 hours or less. Chronic exposures defined as exposures occurring over $>8$ hours accounted for $2.3 \%$ (453) of all human exposures. Acute on chronic exposures defined as single exposure that was preceded by a chronic exposure over $>8$ hours totaled 2,258 (11.6\%). Ingestion was the most common route of exposure $(85.3 \%, \mathrm{n}=16,548)$ documented in all cases (Table 4).

The most commonly reported substance in those less than six years of age was cosmetics/personal care products $(n=959)$, followed closely by household cleaning products $(n=943)$. Table 5 lists the substances most frequently involved in exposures for those $\leq 5$ years old. For adult cases (> 19 years of age), analgesics $(n=1,296)$ and sedative/hypnotics/antipsychotics $(\mathrm{n}=1,084)$ were the most frequently involved substances as seen in Table 6. Among all encounters, analgesics ( $\mathrm{n}=2,805,11.6 \%)$ were the most frequently encountered substance category. Table 7 (available online only at "journals.ku.edu/ kjm”) is a summary log for all exposures categorized by category and sub-category of substance.

In 2019, there was a total of 331 plant exposures reported to the KSPCC. The single most common plant exposure encountered was to pokeweed (Phytolacca Americana; $\mathrm{n}=28$ ). Table 8 lists the top 5 most encountered plants. 


\section{KANSAS JOURNAL of MEDICINE}

2019 KSPCC REPORT

continued.

Table 2. Distribution of human exposures by age and gender.

\begin{tabular}{|c|c|c|c|c|c|c|c|c|c|c|}
\hline & \multicolumn{2}{|c|}{ Male } & \multicolumn{2}{|c|}{ Female } & \multicolumn{2}{|c|}{ Unknown gender } & \multicolumn{2}{|c|}{ Total } & \multicolumn{2}{|c|}{ Cumulative total } \\
\hline Age (yrs) & $\mathbf{N}$ & $\begin{array}{c}\% \text { of age } \\
\text { group total }\end{array}$ & $\mathbf{N}$ & $\begin{array}{c}\text { \% of age } \\
\text { group total }\end{array}$ & $\mathbf{N}$ & $\begin{array}{c}\% \text { of age } \\
\text { group total }\end{array}$ & $\mathbf{N}$ & $\begin{array}{l}\text { \% of total } \\
\text { exposure }\end{array}$ & $\mathbf{N}$ & $\%$ \\
\hline$<1$ year & 525 & 55.09 & 426 & 44.70 & 2 & 0.21 & 953 & 4.91 & 953 & 4.91 \\
\hline 1 year & 1,479 & 53.51 & 1,282 & 46.38 & 3 & 0.11 & 2,764 & 14.24 & 3,717 & 19.15 \\
\hline 2 years & 1,463 & 54.94 & 1,199 & 45.02 & 1 & 0.04 & 2,663 & 13.72 & 6,380 & 32.88 \\
\hline 3 years & 742 & 58.94 & 517 & 41.06 & 0 & 0.00 & 1,259 & 6.49 & 7,639 & 39.36 \\
\hline 4 years & 385 & 58.07 & 277 & 41.78 & 1 & 0.15 & 663 & 3.42 & 8,302 & 42.78 \\
\hline 5 years & 202 & 55.04 & 145 & 39.51 & 20 & 5.45 & 367 & 1.89 & 8,669 & 44.67 \\
\hline $\begin{array}{l}\text { Unknown } \leq 5 \\
\text { years }\end{array}$ & 0 & 0.00 & 0 & 0.00 & 1 & 100.00 & 1 & 0.01 & 8,670 & 44.68 \\
\hline $\begin{array}{l}\text { Child 6 - } 12 \\
\text { years }\end{array}$ & 637 & 49.30 & 540 & 41.80 & 115 & 8.90 & 1,292 & 6.66 & 9,962 & 51.33 \\
\hline $\begin{array}{l}\text { Teen } 13 \text { - } 19 \\
\text { years }\end{array}$ & 736 & 38.57 & 1,169 & 61.27 & 3 & 0.16 & 1,908 & 9.83 & 11,870 & 61.17 \\
\hline Unknown child & 3 & 50.00 & 2 & 33.33 & 1 & 16.67 & 6 & 0.03 & 11,876 & 61.20 \\
\hline Subtotal & 6,172 & 51.97 & $\mathbf{5 , 5 5 7}$ & 46.79 & 147 & 1.24 & 11,876 & 61.20 & 11,876 & 61.20 \\
\hline 20 - 29 years & 893 & 45.72 & 1,058 & 54.17 & 2 & 0.10 & 1,953 & 10.06 & 13,829 & 71.26 \\
\hline 30 - 39 years & 791 & 47.56 & 872 & 52.44 & 0 & 0.00 & 1,663 & 8.57 & 15,492 & 79.83 \\
\hline 40 - 49 years & 450 & 40.14 & 670 & 59.77 & 1 & 0.09 & 1,121 & 5.78 & 16,613 & 85.61 \\
\hline $50-59$ years & 420 & 40.15 & 624 & 59.66 & 2 & 0.19 & 1,046 & 5.39 & 17,659 & 91.00 \\
\hline $60-69$ years & 307 & 40.66 & 447 & 59.21 & 1 & 0.13 & 755 & 3.89 & 18,414 & 94.89 \\
\hline 70 - 79 years & 240 & 43.32 & 314 & 56.68 & 0 & 0.00 & 554 & 2.85 & 18,968 & 97.74 \\
\hline 80 - 89 years & 102 & 38.49 & 163 & 61.51 & 0 & 0.00 & 265 & 1.37 & 19,233 & 99.11 \\
\hline$\geq 90$ years & 26 & 40.00 & 39 & 60.00 & 0 & 0.00 & 65 & 0.33 & 19,298 & 99.44 \\
\hline Unknown adult & 42 & 45.65 & 44 & 47.83 & 6 & 6.52 & 92 & 0.47 & 19,390 & 99.92 \\
\hline Subtotal & 3,271 & 43.53 & 4,231 & 56.31 & 12 & 0.16 & 7,514 & 38.72 & 19,390 & 99.92 \\
\hline Unknown age & 5 & 31.25 & 2 & 12.50 & 9 & 56.25 & 16 & 0.08 & 19,406 & 100.00 \\
\hline Total & 9,448 & 48.69 & 9,790 & 50.45 & 168 & 0.87 & 19,406 & 100.00 & 19,406 & 100.00 \\
\hline
\end{tabular}

Table 3. Origin of call and site of exposure for human exposure cases.

\begin{tabular}{|l|c|c|c|c|}
\hline \multicolumn{1}{|c|}{ Site } & \multicolumn{2}{c|}{ Origin of call } & \multicolumn{2}{c|}{ Site of exposure } \\
\hline & $\mathbf{N}$ & $\boldsymbol{\%}$ & $\mathbf{N}$ & $\%$ \\
\hline Residence & & & & \\
\hline Own & 12,257 & 63.16 & 17,170 & 88.48 \\
\hline Other & 342 & 1.76 & 610 & 3.14 \\
\hline Workplace & 282 & 1.45 & 476 & 2.45 \\
\hline Health care facility & 5,195 & 26.77 & 111 & 0.57 \\
\hline School & 37 & 0.19 & 468 & 2.41 \\
\hline Restaurant/food service & 1 & 0.01 & 49 & 0.25 \\
\hline Public area & 70 & 0.36 & 173 & 0.89 \\
\hline Other & 1,208 & 6.22 & 223 & 1.15 \\
\hline Unknown & 14 & 0.07 & 126 & 0.65 \\
\hline
\end{tabular}


Table 4. Route of human exposures.*

\begin{tabular}{|l|c|c|c|}
\hline & \multicolumn{3}{|c|}{ Human exposures } \\
\hline Route & $\mathbf{N}$ & \% of All Routes & \% of All Cases \\
\hline Ingestion & 16,548 & 79.97 & 85.27 \\
\hline Dermal & 1,583 & 7.65 & 8.16 \\
\hline Inhalation/Nasal & 1,231 & 5.95 & 6.34 \\
\hline Ocular & 754 & 3.64 & 3.89 \\
\hline Bite/Sting & 184 & 0.89 & 0.95 \\
\hline Parenteral & 172 & 0.83 & 0.89 \\
\hline Unknown & 164 & 0.79 & 0.85 \\
\hline Aspiration (with ingestion) & 23 & 0.11 & 0.12 \\
\hline Otic & 14 & 0.07 & 0.07 \\
\hline Other & 13 & 0.06 & 0.07 \\
\hline Vaginal & 5 & 0.02 & 0.03 \\
\hline Rectal & 2 & 0.01 & 0.01 \\
\hline Total Number of Routes & $\mathbf{2 0 , 6 9 3}$ & $\mathbf{1 0 0 . 0 0}$ & $\mathbf{1 0 6 . 6 3}$ \\
\hline
\end{tabular}

*Some cases may have multiple routes of exposure documented.

Table 5. Substance categories most frequently involved in exposures for age $\leq 5$ years old.

\begin{tabular}{|c|c|c|c|c|c|}
\hline Substance category & Previous year rank & All substance & $\%$ & Single substance exposures & $\%$ \\
\hline Cosmetics/personal care products & 1 & 959 & 10.48 & 929 & 11.12 \\
\hline Cleaning substances (household) & 2 & 943 & 10.31 & 903 & 10.81 \\
\hline Analgesics & 3 & 827 & 9.04 & 747 & 8.94 \\
\hline Foreign bodies/toys/miscellaneous & 4 & 533 & 5.83 & 517 & 6.19 \\
\hline Antihistamines & 5 & 503 & 5.50 & 463 & 5.54 \\
\hline Dietary supplements/herbals/homeopathic & 6 & 496 & 5.42 & 464 & 5.55 \\
\hline Topical preparations & 8 & 382 & 4.17 & 377 & 4.51 \\
\hline Vitamins & 7 & 378 & 4.13 & 326 & 3.90 \\
\hline Pesticides & 9 & 349 & 3.81 & 327 & 3.91 \\
\hline Gastrointestinal preparations & 10 & 217 & 2.37 & 181 & 2.17 \\
\hline Cardiovascular drugs & 12 & 216 & 2.36 & 121 & 1.45 \\
\hline Plants & 15 & 199 & 2.17 & 193 & 2.31 \\
\hline Hormones and hormone antagonists & 16 & 197 & 2.15 & 123 & 1.47 \\
\hline Electrolytes and minerals & 17 & 185 & 2.02 & 168 & 2.01 \\
\hline Essential oils & 13 & 176 & 1.92 & 165 & 1.97 \\
\hline
\end{tabular}

Table 6. Substance categories most frequently involved in exposures of adults ( $>19$ years).

\begin{tabular}{|l|c|c|c|c|}
\hline Substance category & All substances & $\%$ & Single substance exposures & $\%$ \\
\hline Analgesics & 1,296 & 11.83 & 551 & 9.72 \\
\hline Sedative/hypnotics/antipsychotics & 1,084 & 9.89 & 337 & 5.94 \\
\hline Antidepressants & 945 & 8.63 & 325 & 5.73 \\
\hline Cardiovascular drugs & 757 & 6.91 & 244 & 4.30 \\
\hline Alcohols & 601 & 5.49 & 67 & 1.18 \\
\hline Antihistamines & 476 & 4.34 & 209 & 3.69 \\
\hline Cleaning substances (household) & 444 & 4.05 & 356 & 6.28 \\
\hline Pesticides & 434 & 3.96 & 334 & 5.89 \\
\hline Anticonvulsants & 410 & 3.74 & & 2.08 \\
\hline
\end{tabular}




\section{KANSAS JOURNAL of MEDICINE}

\section{KSPCC REPORT}

continued.

Table 6. Substance categories most frequently involved in exposures of adults ( $>19$ years). continued.

\begin{tabular}{|l|c|c|c|c|}
\hline Substance category & All substances & $\%$ & Single substance exposures & $\%$ \\
\hline Hormones and hormone antagonists & 342 & 3.12 & 186 & 3.28 \\
\hline Stimulants and street drugs & 335 & 3.06 & 149 & 2.63 \\
\hline Fumes/gases/vapors & 295 & 2.69 & 268 & 4.73 \\
\hline Chemicals & 294 & 2.68 & 254 & 4.48 \\
\hline Muscle relaxants & 236 & 2.15 & 90 & 1.59 \\
\hline Cold and cough preparations & 228 & 2.08 & 106 & 1.87 \\
\hline
\end{tabular}

Table 8. Top 5 most frequent plant exposures.

\begin{tabular}{|l|c|}
\hline Botanical name or category & N \\
\hline Oxalates (species unspecified) & 38 \\
\hline Plants: non-toxic & 33 \\
\hline Phytolacca Americana (L.) (botanic name) & 28 \\
\hline Cherry (species unspecified, wild \& domesticated) & 22 \\
\hline Plants-general-unknown & 11 \\
\hline Spathiphyllum species (botanic name) & 10 \\
\hline Poison ivy/oak & 9 \\
\hline Philodendron (species unspecified) & 7 \\
\hline Total of all plant calls & $\mathbf{3 3 1}$ \\
\hline
\end{tabular}

Unintentional exposures were the most common reason for exposures $(75.4 \%, \mathrm{n}=14,634)$ while intentional exposures accounted for $21.3 \%(\mathrm{n}=4,127)$ of exposures. Table 9 lists reasons for human exposures. Most unintentional exposures, $58.8 \%(\mathrm{n}=8,609)$ occurred in the $\leq 5$-years-old age group. In patients less than 13 years of age, $97.8 \%$ $(\mathrm{n}=9,745)$ of ingestions were unintentional. However, in the age 13 to 19-years-old group, intentional exposure was most common $(67.2 \%, \mathrm{n}$ $=1,283)$. In total, suspected suicide attempts accounted for $16.5 \%(\mathrm{n}=$ 3,201 ) of human encounters. When a therapeutic error was the reason for exposure, a double dose was the most common scenario, $32.2 \%$ (n $=756$ ).

Most encounters $(65.9 \%, \mathrm{n}=12,780)$ were managed in a nonhealth care facility (i.e., a residence). Of the 6,368 encounters managed at a health care facility, $45 \%(\mathrm{n}=2,863)$ were admitted. Table 10 lists the management site of all human encounters.

Among human exposures, 14,591 involved exposures to pharmaceutical agents while 9,439 involved exposure to non-pharmaceuticals. Because an encounter could include numerous pharmaceutical agents and non-pharmaceutical agents, this total was greater than the total number of encounters. However, $86 \%(n=16,683)$ of all human exposures were exposed to only a single substance. Among these single substance exposures, the reason for exposure was intentional in $25.6 \%(n=2,160)$ of pharmaceutical-only cases compared to $3.8 \%(\mathrm{n}=316)$ of non-pharmaceutical single substance exposures.

When medical outcomes were analyzed, $26.4 \%(n=5,116)$ of human exposures had no effect, $18.8 \%(\mathrm{n}=3,652)$ had minor effect, 9.3\% ( $\mathrm{n}=1,813)$ had moderate effect, and 3.1\% $(\mathrm{n}=603)$ had major effects. Moderate effects were more common in the 13 to 19 -yearold group while major effects were more common in those over 20 years of age. Moderate and major effects were most common in those with intentional encounters. More serious outcomes were related to single-substance pharmaceutical exposures, accounting for $35.7 \%$ (n $=5$ ) of the fatalities. Table 11 lists all medical outcomes by age and Table 12 lists outcomes by reason for exposure.

Use of decontamination and specific therapies, including antidotal therapy, is detailed in Tables 13a and 13b (tables available online only at "journals.ku.edu/kjm"). There were 14 deaths in 2019 reported to the KSPCC. All deaths involved patients 20 years of age or older, and 11 of the deaths involved intentional exposures. Table 14 details the 14 reported deaths (available online only at "journals.ku.edu/kjm”).

Table 15 compares key statistics from 2015 to 2019. Overall case volumes have declined since 2016, however, the percentage of calls from healthcare facilities, and cases with moderate or major outcomes have increased steadily from 2015 to 2019. The number of deaths doubled from 2018 to 2019.

\section{DISCUSSION}

The ongoing importance of the KSPCC is reflected in trends that have seen rates of poisonings and overdoses increase at an alarming rate over the last decade. According to the Annual Surveillance Report of Drug-Related Risks and Outcomes, drug poisoning-related hospitalizations in the United States have increased $26 \%$ in over the last two years that data are available., The National Center for Health Statistics noted over 67,000 overdose related deaths in $2018 .{ }^{3}$ 
Table 9. Reasons for human exposure cases.

\begin{tabular}{|c|c|c|}
\hline Unintentional & Exposures & $\%$ of Total \\
\hline Unintentional - general & 9,242 & 47.6 \\
\hline Unintentional - therapeutic error & 2,342 & 12.1 \\
\hline Unintentional - misuse & 1,705 & 8.8 \\
\hline Unintentional - environmental & 630 & 3.2 \\
\hline Unintentional - occupational & 379 & 2.0 \\
\hline Unintentional - bite/sting & 184 & 0.9 \\
\hline Unintentional - food poisoning & 124 & 0.6 \\
\hline Unintentional - unknown & 28 & 0.1 \\
\hline Subtotal & 14,634 & 75.4 \\
\hline \multicolumn{3}{|l|}{ Intentional } \\
\hline Intentional - suspected suicide & 3,201 & 16.5 \\
\hline Intentional - misuse & 474 & 2.4 \\
\hline Intentional - abuse & 375 & 1.9 \\
\hline Intentional - unknown & 77 & 0.4 \\
\hline Subtotal & 4,127 & 21.3 \\
\hline \multicolumn{3}{|l|}{ Adverse Reaction } \\
\hline Adverse reaction - drug & 301 & 1.6 \\
\hline Adverse reaction - food & 70 & 0.4 \\
\hline Adverse reaction - other & 61 & 0.3 \\
\hline Subtotal & 432 & 2.2 \\
\hline \multicolumn{3}{|l|}{ Unknown } \\
\hline Unknown reason & 121 & 0.6 \\
\hline Subtotal & 121 & 0.6 \\
\hline \multicolumn{3}{|l|}{ Other } \\
\hline Other - malicious & 73 & 0.4 \\
\hline Other - withdrawal & 14 & 0.1 \\
\hline Other - contamination/tampering & 5 & 0.0 \\
\hline Subtotal & 92 & 0.5 \\
\hline Total & 19,406 & 100.0 \\
\hline
\end{tabular}

Table 10. Management site of human exposures.

\begin{tabular}{|c|c|c|}
\hline Site of management & $\mathbf{N}$ & $\%$ \\
\hline Managed in healthcare facility & & \\
\hline Treated/evaluated and released & 3,241 & 16.7 \\
\hline Admitted to critical care unit & 1,421 & 7.3 \\
\hline Admitted to noncritical care unit & 836 & 4.3 \\
\hline Admitted to psychiatric facility & 606 & 3.1 \\
\hline Patient lost to follow-up/left AMA & 264 & 1.4 \\
\hline Subtotal (managed in healthcare facility) & $\mathbf{6 , 3 6 8}$ & $\mathbf{3 2 . 8}$ \\
\hline Managed on site, non-healthcare facility & 12,780 & 65.9 \\
\hline Other & 30 & 0.2 \\
\hline Refused referral & 217 & 1.1 \\
\hline Unknown & 11 & 0.1 \\
\hline Total & $\mathbf{1 9 , 4 0 6}$ & $\mathbf{1 0 0 . 0}$ \\
\hline
\end{tabular}

\section{KANSAS JOURNAL of MEDICINE}

2019 KSPCC REPORT

continued.
Similarly, the KSPCC consistently has seen an increase in the number of cases from healthcare facilities and cases with moderate or major medical outcomes. Over the last five years, calls from healthcare facilities have increased by $22 \%$ while moderate/major outcomes increased by $43 \%$. Cases from healthcare facilities account for more than $25 \%$ of the cases reported to the KSPCC. ${ }^{4-6}$ While the number of deaths doubled from 7 in 2018 to 14 in 2019, this more closely reflects previous years' exposure-related fatalities with 15 and 16 deaths documented in 2016 and 2017, respectively.,5

The 2019 Kansas Poison Control Center at The University of Kansas Health System's statistics continued to mirror those seen nationally by the other 54 accredited poison control centers nationwide. In $2018,2,530,238$ encounters were logged by poison control, including 2,099,751 human exposures. ${ }^{7}$ Overall encounters showed a 2.96\% (n $=77,175$ ) decline from 2017 to 2018 , though healthcare facility human exposure cases decreased by only $0.261 \%$ from 2017. More serious outcomes (moderate, major, or death) continued to increase. Nationwide, the five substance classes most frequently involved in adult exposures were analgesics, sedative/hypnotics/antipsychotics, antidepressants, cardiovascular drugs, and cleaning substances (household), while the top five most common exposures in children age five years or less were cosmetics/personal care products, household cleaning substances, analgesics, foreign bodies/toys/miscellaneous, and topical preparations. There were 3,11l exposure-related fatalities reported nationwide in 2018.

Several important limitations must be noted when interpreting poison center data. Reporting exposures to the KSPCC is voluntary and the KSPCC is not contacted regarding all poisonings in the state of Kansas. Furthermore, in most cases, there is no objective confirmation of exposure.

\section{CONCLUSIONS}

The 2019 KSPCC annual report demonstrated that the center received over 20,000 total calls, including more than 19,000 human exposures. While pediatric exposures remain the most common, there continues to be an increasing trend in the number of calls from healthcare facilities and for cases with serious outcomes. In this regard, the experience of the KSPCC is similar to national data. This report supported the continued value of the KSPCC to both public and acute healthcare in the state of Kansas.

\section{ACKNOWLEDGMENTS}

The authors knowledge the Poison Control Center Staff: AnneMarie Banks, Damien Emley, Anita Farris, Mark Stallbaumer, Robert Stockdale, and Connor Bowman. 


\section{KANSAS JOURNAL of MEDICINE}

\section{KSPCC REPORT}

continued.

Table 11. Medical outcome of human exposure cases by patient age.

\begin{tabular}{|c|c|c|c|c|c|c|c|c|c|c|c|c|c|c|c|c|}
\hline & \multicolumn{2}{|c|}{$\leq 5$ years } & \multicolumn{2}{|c|}{6 - 12 years } & \multicolumn{2}{|c|}{13 - 19 years } & \multicolumn{2}{|c|}{$\geq 20$ years } & \multicolumn{2}{|c|}{ Unknown child } & \multicolumn{2}{|c|}{ Unknown adult } & \multicolumn{2}{|c|}{ Unknown age } & \multicolumn{2}{|c|}{ Total } \\
\hline Outcome & $\mathbf{N}$ & $\%$ & $\mathbf{N}$ & $\%$ & $\mathbf{N}$ & $\%$ & $\mathbf{N}$ & $\%$ & $\mathbf{N}$ & $\%$ & $\mathbf{N}$ & $\%$ & $\mathbf{N}$ & $\%$ & $\mathbf{N}$ & $\%$ \\
\hline No effect & 2,931 & 33.81 & 402 & 31.11 & 435 & 22.80 & 1,331 & 17.93 & 1 & 16.67 & 11 & 11.96 & 5 & 31.3 & 5,116 & 26.36 \\
\hline Minor effect & 957 & 11.04 & 239 & 18.50 & 589 & 30.87 & 1,854 & 24.98 & 0 & 0.00 & 13 & 14.13 & 0 & 0.0 & 3,652 & 18.82 \\
\hline Moderate effect & 85 & 0.98 & 42 & 3.25 & 396 & 20.75 & 1,285 & 17.31 & 0 & 0.00 & 4 & 4.35 & 1 & 6.3 & 1,813 & 9.34 \\
\hline Major effect & 18 & 0.21 & 7 & 0.54 & 97 & 5.08 & 479 & 6.45 & 0 & 0.00 & 2 & 2.17 & 0 & 0.0 & 603 & 3.11 \\
\hline Death & 0 & 0.00 & $\overline{0}$ & 0.00 & 0 & 0.00 & 14 & 0.19 & 0 & 0.00 & 0 & 0.00 & 0 & 0.0 & 14 & 0.07 \\
\hline $\begin{array}{l}\text { No follow-up, } \\
\text { nontoxic }\end{array}$ & 310 & 3.58 & 30 & 2.32 & 10 & 0.52 & 20 & 0.27 & 1 & 16.67 & 2 & 2.17 & 0 & 0.0 & 373 & 1.92 \\
\hline $\begin{array}{l}\text { No follow-up, } \\
\text { minimal toxicity }\end{array}$ & 4,019 & 46.36 & 518 & 40.09 & 283 & 14.83 & 1,717 & 23.13 & 2 & 33.33 & 31 & 33.70 & 3 & 18.8 & 6,573 & 33.87 \\
\hline $\begin{array}{l}\text { No follow-up, } \\
\text { potentially toxic }\end{array}$ & 220 & 2.54 & 31 & 2.40 & 64 & 3.35 & 355 & 4.78 & 2 & 33.33 & 28 & 30.43 & 7 & 43.8 & 707 & 3.64 \\
\hline Unrelated effect & 130 & 1.50 & 23 & 1.78 & 34 & 1.78 & 367 & 4.94 & 0 & 0.00 & 1 & 1.09 & 0 & 0.0 & 555 & 2.86 \\
\hline $\begin{array}{l}\text { Death, indirect } \\
\text { report }\end{array}$ & 0 & 0.00 & 0 & 0.00 & 0 & 0.00 & 0 & 0.00 & 0 & 0.00 & 0 & 0.00 & 0 & 0.0 & 0 & 0.00 \\
\hline Total & 8,670 & 100.00 & 1,292 & 100.00 & 1,908 & 100.00 & 7,422 & 100.00 & 6 & 100.00 & 92 & 100.00 & 16 & 100.00 & 19,406 & 100.00 \\
\hline
\end{tabular}

Table 12. Medical outcome by reason for exposure in human exposures.

\begin{tabular}{|l|c|c|c|c|c|c|c|c|c|c|c|c|}
\hline & \multicolumn{1}{|c|}{ Unintentional } & \multicolumn{2}{c|}{ Intentional } & \multicolumn{2}{|c|}{ Other } & \multicolumn{2}{|c|}{ Adverse reaction } & \multicolumn{2}{|c|}{ Unknown } & \multicolumn{2}{|c|}{ Total } \\
\hline \multicolumn{1}{|c|}{ Outcome } & $\mathbf{N}$ & $\mathbf{\%}$ & $\mathbf{N}$ & $\mathbf{\%}$ & $\mathbf{N}$ & $\mathbf{\%}$ & $\mathbf{N}$ & $\mathbf{\%}$ & $\mathbf{N}$ & $\mathbf{\%}$ & $\mathbf{N}$ & $\mathbf{\%}$ \\
\hline Death & 3 & 0.02 & 11 & 0.27 & 0 & 0.00 & 0 & 0.00 & 0 & 0.00 & 14 & 0.07 \\
\hline $\begin{array}{l}\text { Death, indirect } \\
\text { report }\end{array}$ & 0 & 0.00 & 0 & 0.00 & 0 & 0.00 & 0 & 0.00 & 0 & 0.00 & 0 & 0.00 \\
\hline Major effect & 75 & 0.51 & 489 & 11.85 & 0 & 0.00 & 13 & 3.01 & 26 & 21.49 & 603 & 3.11 \\
\hline Minor effect & 2,392 & 16.35 & 1,105 & 26.77 & 18 & 19.57 & 119 & 27.55 & 18 & 14.88 & 3,652 & 18.82 \\
\hline Moderate effect & 483 & 3.30 & 1,253 & 30.36 & 9 & 9.78 & 41 & 9.49 & 27 & 22.31 & 1,813 & 9.34 \\
\hline No effect & 4,191 & 28.64 & 871 & 21.10 & 9 & 9.78 & 31 & 7.18 & 14 & 11.57 & 5,116 & 26.36 \\
\hline $\begin{array}{l}\text { No follow-up, } \\
\text { nontoxic }\end{array}$ & 364 & 2.49 & 5 & 0.12 & 1 & 1.09 & 2 & 0.46 & 1 & 0.83 & 373 & 1.92 \\
\hline $\begin{array}{l}\text { No follow-up, } \\
\text { minimal toxicity }\end{array}$ & 6,288 & 42.97 & 153 & 3.71 & 19 & 20.65 & 106 & 24.54 & 7 & 5.79 & 6,573 & 33.87 \\
\hline $\begin{array}{l}\text { No follow-up, } \\
\text { potentially toxic }\end{array}$ & 461 & 3.15 & 180 & 4.36 & 18 & 19.57 & 35 & 8.10 & 13 & 10.74 & 707 & 3.64 \\
\hline Unrelated effect & 377 & 2.58 & 60 & 1.45 & 18 & 19.57 & 85 & 19.68 & 15 & 12.40 & 555 & 2.86 \\
\hline Total & $\mathbf{1 4 , 6 3 4}$ & $\mathbf{1 0 0 . 0 0}$ & $\mathbf{4 , 1 2 7}$ & $\mathbf{1 0 0 . 0 0}$ & $\mathbf{9 2}$ & $\mathbf{1 0 0 . 0 0}$ & $\mathbf{4 3 2}$ & $\mathbf{1 0 0 . 0 0}$ & $\mathbf{1 2 1}$ & $\mathbf{1 0 0 . 0 0}$ & $\mathbf{1 9 , 4 0 6}$ & $\mathbf{1 0 0 . 0 0}$ \\
\hline
\end{tabular}

Table 15. 2015 to 2019 comparison of select statistics.

\begin{tabular}{|l|c|c|c|c|c|}
\hline & $\mathbf{2 0 1 5}$ & $\mathbf{2 0 1 6}$ & $\mathbf{2 0 1 7}$ & $\mathbf{2 0 1 8}$ & $\mathbf{2 0 1 9}$ \\
\hline Total cases & 20,109 & 21,965 & 21,431 & 21,072 & 20,589 \\
\hline Calls from healthcare facility & 4,267 & 4,514 & 4,892 & 5,224 & 5,195 \\
\hline Moderate or major outcomes & 1,688 & 1,971 & 2,170 & 2,340 & 2,416 \\
\hline Deaths & 13 & 15 & 16 & 7 & 14 \\
\hline
\end{tabular}




\section{REFERENCES}

${ }^{1}$ US Centers for Disease Control and Prevention. Annual Surveillance Report of Drug-Related Risks and Outcomes - United States, 2018. August 31, 2018. https://www.cdc.gov/drugoverdose/pdf/pubs/2018-cdc-drugsurveillance-report.pdf?s_cid=cs_828. Accessed September 23, 2020.

2 US Centers for Disease Control and Prevention. 2019 Annual Surveillance Report of Drug-Related Risks and Outcomes - United States Surveillance Special Report. November 1, 2019. https://www.cdc.gov/drugoverdose/ pdf/pubs/2019-cdc-drug-surveillance-report.pdf. Accessed September 23, 2020.

3 Hedegaard H, Miniño AM, Warner M. Drug Overdose Deaths in the United States, 1999-2018. National Center for Health Statistics. Data Brief, no. 356. 2020. https://www.cdc.gov/nchs/data/databriefs/db356-h.pdf. Accessed September 23, 2020.

${ }^{4}$ Silver E, Oller LK, Coons DM, Thornton SL. 2018 Annual Report of the University of Kansas Health System Poison Control Center. Kans J Med 2020; 13:90-100. PMID: 32499861.

5 Oller LK, Coons DM, Thornton SL. 2017 Annual Report of the University of Kansas Health System Poison Control Center. Kans J Med 2019; 12(3):70-79. PMID: 31489103.

6 Thornton SL, Oller L, Coons DM. 2016 Annual Report of the University of Kansas Health System Poison Control Center. Kans J Med 2018; 11(2):1-23. PMID: 2979615l

7 Gummin DD, Mowry JB, Spyker DA, et. al. 2018 Annual Report of the American Association of Poison Control Centers' National Poison Data System (NPDS): 36th Annual Report. Clin Toxicol (Phila) 2019; 57(12):1220-1413. PMID: 31752545.

Keywords: drug overdose, poisoning, ingestion, toxicology, antidotes
KANSAS JOURNAL of MEDIC INE

2019 KSPCC REPORT

continued. 